\title{
All-Cause Mortality Risk of Metabolically Healthy Obese Individuals in NHANES III
}

\author{
C. M. Durward, T. J. Hartman, and S. M. Nickols-Richardson \\ Department of Nutritional Sciences, The Pennsylvania State University, 110 Chandlee Building, University Park, PA 16801, USA \\ Correspondence should be addressed to S. M. Nickols-Richardson, smn13@psu.edu
}

Received 1 August 2012; Revised 29 October 2012; Accepted 29 October 2012

Academic Editor: Jack A. Yanovski

Copyright () 2012 C. M. Durward et al. This is an open access article distributed under the Creative Commons Attribution License, which permits unrestricted use, distribution, and reproduction in any medium, provided the original work is properly cited.

Mortality risk across metabolic health-by-BMI categories in NHANES-III was examined. Metabolic health was defined as: (1) homeostasis model assessment-insulin resistance (HOMA-IR) $<2.5$; (2) $\leq 2$ Adult Treatment Panel (ATP) III metabolic syndrome criteria; (3) combined definition using $\leq 1$ of the following: HOMA-IR $\geq 1.95$ (or diabetes medications), triglycerides $\geq 1.7 \mathrm{mmol} / \mathrm{L}, \mathrm{HDL}-\mathrm{C}<1.04 \mathrm{mmol} / \mathrm{L}$ (males) or $<1.30 \mathrm{mmol} / \mathrm{L}$ (females), LDL-C $\geq 2.6 \mathrm{mmol} / \mathrm{L}$, and total cholesterol $\geq 5.2 \mathrm{mmol} / \mathrm{L}$ (or cholesterol-lowering medications). Hazard ratios (HR) for all-cause mortality were estimated with Cox regression models. Nonpregnant women and men were included $\left(n=4373\right.$, mean \pm SD, age $37.1 \pm 10.9$ years, BMI $\left.27.3 \pm 5.8 \mathrm{~kg} / \mathrm{m}^{2}, 49.4 \% \mathrm{female}\right)$. Only 40 of 1160 obese individuals were identified as MHO by all definitions. MHO groups had superior levels of clinical risk factors compared to unhealthy individuals but inferior levels compared to healthy lean groups. There was increased risk of allcause mortality in metabolically unhealthy obese participants regardless of definition (HOMA-IR HR 2.07 (CI 1.3-3.4), $P<0.01$; ATP-III HR 1.98 (CI 1.4-2.9), $P<0.001$; combined definition HR 2.19 (CI 1.3-3.8), $P<0.01$ ). MHO participants were not significantly different from healthy lean individuals by any definition. While MHO individuals are not at significantly increased risk of all-cause mortality, their clinical risk profile is worse than that of metabolically healthy lean individuals.

\section{Introduction}

Although obesity increases the risk for many chronic diseases, including type 2 diabetes, hypertension, coronary heart disease, stroke, and several types of cancer, not all people with obesity develop a chronic disease [1-3]. Recently, a subset of individuals with obesity who are free of chronic disease, or even the metabolic disturbances thought to be precursors of these diseases, has been identified in the research literature [4-6]. This population is characterized by high insulin sensitivity, favorable cholesterol levels, and normal blood pressure, despite excess adiposity, and has been termed metabolically healthy obese (MHO) [5, 7]. In the United States (US), estimates of prevalence range from approximately 6 to $32 \%$ of obese adults [8-10]. Interest in further understanding the MHO subset of the population is growing, due to the potential to identify novel insights into the mechanisms of chronic diseases and to translate findings into treatment options. However, it remains unclear whether $\mathrm{MHO}$ individuals are protected from the higher risk of chronic diseases and total mortality typically associated with obesity $[1,2,11]$, as some studies demonstrate protection while other investigations suggest that $\mathrm{MHO}$ represents a delay in disease progression in this subpopulation [10]. Answers to such questions would have important implications for public health policy; however, the current literature is equivocal $[12,13]$.

Several longitudinal studies of chronic disease development in $\mathrm{MHO}$ individuals have shown no elevated risk of disease event [14-19]. For example, St-Pierre and colleagues [15] prospectively followed a cohort of 1824 Canadian men for 13 years. They found that obese men with less than three features of the insulin resistance syndrome (i.e., $\mathrm{MHO}$ ) were not at increased risk for heart disease [15]. Hosseinpanah and colleagues [16] found similar results in a sample of 6215 Iranian adults. After eight years of followup, MHO participants were not at elevated risk of cardiovascular disease (CVD) compared to metabolically healthy lean participants [16]. In contrast, a prospective study by Ärnlöv and colleagues [19] found that MHO was 
associated with increased risk of CVD and death after 30 years of followup in 1758 middle-aged men in Sweden. However, this study [19] has been criticized for failing to include important covariates such as socioeconomic status [20].

Results are equivocal in the four studies that have examined risk of mortality in $\mathrm{MHO}$ individuals. In agreement with Ärnlöv and colleagues [19], Kuk and Ardern [10] found an increased risk of all-cause mortality in 6011 adult men and women, ages 18-65 years, with MHO compared to metabolically healthy lean individuals after eight years of followup in the National Health and Nutrition Examination Survey (NHANES) III [10]. This study used both a homeostasis model assessment-insulin resistance (HOMAIR) cutoff of $<2.5$ as well as $\leq 1$ metabolic syndrome criteria to define metabolic health [10]. In contrast, Calori and colleagues [21] found no increased risk of all-cause, CVD, or cancer mortality in MHO individuals when compared to nonobese healthy individuals. This study prospectively followed 2011 middle-aged Italian men and women (the Cremona Cohort) for 15 years [21]. They defined metabolic health using a HOMA-IR cutoff of $<2.5$ as well as the bottom tertile and bottom quartile of HOMA-IR within this sample [21]. Finally, Ortega and colleagues [22] examined total mortality and CVD mortality in a subsample of 43,265 adult men and women in the Aerobics Center Longitudinal Study. Participants were $24.3 \%$ female, 98\% Caucasian, and highly educated. Individuals entered the study between 1979 and 2003, and the median follow-up time for total mortality was 14.3 years. Metabolic health was defined using the International Diabetes Federation definition of metabolic syndrome, excluding waist circumference (WC) criteria [22]. Adiposity was defined as body fat $\geq 25 \%$ for men and $\geq 30 \%$ for women. Ortega and colleagues [22] found that after adjusting for age, sex, examination year, smoking, alcohol consumption, parental history of CVD, and fitness, $\mathrm{MHO}$ participants did not have elevated risk of total or CVD mortality compared to the lean healthy group. An earlier analysis of this cohort at approximately 10 years of followup produced similar results [23].

Overall, variation across findings is not surprising considering the wide variety of samples, follow-up times, primary outcomes, and adjustment (or lack of) for relevant covariates. Another source of variation comes from the use of different definitions of metabolic health. In the MHO literature, there is no consensus definition of metabolic health [24]. Researchers have defined metabolic health in three general ways: insulin resistance measures, metabolic syndrome criteria, or a combination of insulin resistance and metabolic syndrome-type criteria. A review of the literature identified over 30 different definitions of metabolic health, making interpretation of results difficult, and definitive conclusions tenuous. This has led some researchers to use more than one definition in analyses $[10,14,19,25,26]$. This approach allows for improved comparison among studies and examination of the impact of varied definitions on results.

Whether individuals with $\mathrm{MHO}$ are at increased risk for chronic disease and death has important implications for health policy and clinical care. However, available evidence is equivocal, perhaps because of the use of varying definitions of metabolic health. Mortality represents the ultimate adverse outcome of disease; hence, a study that examines how different definitions of metabolic health may affect the relative risk of mortality in adults with $\mathrm{MHO}$ would be useful to resolve these questions. The current study used NHANES III data and linked mortality files to examine differences in mortality outcomes with definitions of MHO proposed in the literature. The purpose of the current study was to test the hypothesis that three currently-used definitions of metabolic health would result in different samples of MHO participants with different risk profiles.

\section{Materials and Methods}

2.1. NHANES III Data and Linked Mortality File. For this investigation, NHANES III data (collected 1988-1994) and the linked mortality file were used [27]. The NHANES is administered by the US Department of Health and Human Services and the US Department of Agriculture. These data are available from the National Center for Health Statistics (NCHS) (http://www.cdc.gov/nchs/nhanes.htm). A nationally representative sample was created using a stratified, multistage, and probability cluster design. Collected data included personal interviews, physical examinations, and laboratory tests. The linked mortality file used probabilistic matching to connect NHANES participants to death records from the National Death Index. The most recent dataset followed participants through 2006, resulting in 12-18 years of followup depending on when participants were initially surveyed by NHANES III. All participants gave written informed consent before participation. The NHANES III study protocol was approved by the NCHS. This secondary analysis of nationally available data was exempt from Institutional Review Board review.

2.2. Sample. The NHANES III datafile includes 33,994 participants ages 2 months and older. For the current analysis, participants needed to be eligible for the linked mortality datafile; thus, participants older than 17 years at the time of survey and with enough identifying information for matching were included. Participants were excluded if they were currently pregnant, breastfeeding, or underweight (body mass index $\left.\left(\mathrm{BMI} ; \mathrm{kg} / \mathrm{m}^{2}\right)<18.5\right)$. To avoid issues of reverse causation due to weight loss in the elderly, participants were also excluded if they were 60 years or older [28]. Finally, to be eligible for this analysis, participants must have provided a morning blood sample after fasting for at least six hours.

2.3. Data Selected from NHANES III. Sex (male and female), age (continuous in years), income $(<\$ 20,000 /$ year, $>\$ 20,000 /$ year), education (years of school), race/ethnicity (non-Hispanic white, non-Hispanic black, Mexican American and other), smoking status (never, current, and former), alcohol consumption (number of drinks per month), marital status (married or living as married, previously married, and never married), leisure time physical activity (number 
of times engaged in leisure time physical activity in past month), and menopausal status ( $\geq 12$ months since last menstrual cycle, $<12$ months since last menstrual cycle) were assessed using self-reported questionnaires [27]. Height was measured using a wall-mounted stadiometer, and weight was measured using a Toledo digital scale in minimal clothing [27]. BMI was calculated from height and weight measurements. Participants were classified as lean (BMI $=$ 18.5-24.9), overweight (BMI $=25-29.9)$, or obese $(B M I=\geq$ 30) based on standard cutoffs [30]. WC was measured at the iliac crest after a normal exhalation of breath [27]. Blood pressure $(\mathrm{mmHg})$ was measured using a mercury sphygmomanometer according to the American Heart Association recommendations. Blood pressure was taken while seated, and up to three measurements were averaged [27].

Blood samples were collected via venipuncture by a phlebotomist. Participants at the morning sessions were instructed to fast for 10-12 hours, though compliance varied [27]. Samples were analyzed for total cholesterol (TC), highdensity lipoprotein cholesterol (HDL-C), triglycerides (TG), glucose, and insulin, using laboratory procedures as reported by NCHS [27]. Low-density lipoprotein cholesterol (LDL-C) was estimated using the following equation [31]:

\section{LDL-C $(\mathrm{mmol} / \mathrm{L})$}

$=[\mathrm{TC}(\mathrm{mmol} / \mathrm{L})]-[\mathrm{HDL}-\mathrm{C}(\mathrm{mmol} / \mathrm{L})]-\left[\frac{\mathrm{TG}(\mathrm{mmol} / \mathrm{L})}{2.17}\right]$.

LDL-C was not calculated for participants who had TG levels $\geq 4.52 \mathrm{mmol} / \mathrm{L}$, because this equation is not accurate at high levels of TG [31]. The following equation was used to estimate insulin resistance [32]:

HOMA-IR $(\mathrm{mmol} / \mathrm{L} \times \mu \mathrm{U} / \mathrm{mL})$

$$
=\frac{\text { fasting glucose }(\mathrm{mmol} / \mathrm{L}) \times \text { fasting insulin }(\mu \mathrm{U} / \mathrm{mL})}{22.5} .
$$

2.4. Definition of Metabolic Health. For the purposes of this analysis, three currently applied definitions of metabolic health were chosen, one from each of the three aforementioned categories (insulin resistance, metabolic syndrome criteria, and combined insulin resistance and metabolic syndrome-type criteria). Definitions of metabolic health (Table 1) included: (1) HOMA-IR cutoff of $<2.5$; (2) $\leq 2$ Metabolic Syndrome Criteria as defined by the Adult Treatment Panel (ATP) III, and (3) a combined definition first introduced by Karelis and colleagues [29] that included a HOMA-IR cutoff and metabolic syndrome-type criteria (Table 1). As shown in Table 1, participants taking lipidlowering medications or diabetes medications were considered to have elevated lipids or glucose and insulin resistance, respectively. Participants who were missing LDL-C levels due to TG levels $\geq 4.52 \mathrm{mmol} / \mathrm{L}$ were coded as unhealthy for the combined definition, assuming that LDL-C values
TABle 1: Definitions of metabolic health.

\begin{tabular}{|c|c|}
\hline \multirow[b]{2}{*}{ HOMA-IR } & Healthy $=<2.5$ \\
\hline & $\begin{array}{l}\text { HOMA-IR }(\mathrm{mmol} / \mathrm{L} \times \mu \mathrm{U} / \mathrm{mL})=\text { fasting glucose } \\
(\mathrm{mmol} / \mathrm{L}) \times \text { fasting insulin }(\mu \mathrm{U} / \mathrm{mL}) / 22.5\end{array}$ \\
\hline \multirow{6}{*}{ ATP-III } & Healthy $=\leq 2$ metabolic syndrome criteria \\
\hline & $\begin{array}{l}\text { Fasting glucose } \geq 5.6 \mathrm{mmol} / \mathrm{L} \text { (or diabetes } \\
\text { medications) }\end{array}$ \\
\hline & $\begin{array}{l}\text { Systolic } \mathrm{BP} \geq 130 \mathrm{mmHg} \text { or diastolic } \\
\mathrm{BP} \geq 85 \mathrm{mmHg} \text { (or antihypertensive medications) }\end{array}$ \\
\hline & $\begin{array}{l}\text { Triglycerides } \geq 1.7 \mathrm{mmol} / \mathrm{L} \text { (or } \\
\text { cholesterol-lowering medications) }\end{array}$ \\
\hline & $\begin{array}{l}\mathrm{HDL}-\mathrm{C}<1.04 \mathrm{mmol} / \mathrm{L} \text { (males), }<1.30 \mathrm{mmol} / \mathrm{L} \\
\text { (females) }\end{array}$ \\
\hline & $\begin{array}{l}\text { Waist circumference }>102 \mathrm{~cm} \text { (males), }>88 \mathrm{~cm} \\
\text { (females) }\end{array}$ \\
\hline \multirow{6}{*}{ Combined } & Healthy $=\leq 1$ criteria (Karelis et al. [29]) \\
\hline & HOMA-IR $\geq 1.95$ (or diabetes medications) \\
\hline & $\begin{array}{l}\text { Triglycerides } \geq 1.7 \mathrm{mmol} / \mathrm{L} \text { (or } \\
\text { cholesterol-lowering medications) }\end{array}$ \\
\hline & $\begin{array}{l}\mathrm{HDL}-\mathrm{C}<1.04 \mathrm{mmol} / \mathrm{L} \text { (males), }<1.30 \mathrm{mmol} / \mathrm{L} \\
\text { (females) }\end{array}$ \\
\hline & $\mathrm{LDL}-\mathrm{C} \geq 2.6 \mathrm{mmol} / \mathrm{L}$ \\
\hline & $\begin{array}{l}\text { Total cholesterol } \geq 5.2 \mathrm{mmol} / \mathrm{L} \text { (or } \\
\text { cholesterol-lowering medications) }\end{array}$ \\
\hline
\end{tabular}

HOMA-IR: homeostasis model assessment-insulin resistance; ATP-III: Adult Treatment Panel-III; BP: blood pressure; HDL-C: high-density lipoprotein cholesterol; LDL-C: low-density lipoprotein cholesterol.

would have been $>2.6 \mathrm{mmol} / \mathrm{L}$. The vast majority of such participants ( 89 of 91 or $98 \%$ ) would have been identified as unhealthy by the combined definition, even without an elevated LDL-C. A cutoff of 2.5 was chosen for HOMA-IR, because this was the median level for proposed definitions and allowed comparison to key past studies $[10,21]$. For metabolic syndrome criteria, $\leq 2$ ATP-III criteria were selected for comparison of findings to metabolic syndrome studies using ATP-III criteria and because $\leq 2$ was the most commonly used cutoff in the MHO literature [14, 19, 33, 34]. (Although not reported here, the current analysis also used $\leq 1$ ATP-III criteria as the definition of metabolic health; the same pattern of results was found.) The specific combined definition used here was chosen from many definitions that combined a marker of insulin resistance with metabolic syndrome-type criteria and because it was the most frequently applied combined definition in the literature $[7,24,35,36]$.

2.5. Statistical Analysis. Survival analysis using Coxproportional hazards regression models (proc surveyphreg) was used to calculate hazard ratios (HR) with 95\% confidence intervals (CI) for metabolically healthy and unhealthy individuals by BMI categories using the chosen definitions of metabolic health. Sex, age, income, education, race/ethnicity, smoking status, alcohol consumption, marital status, leisure time physical activity, and menopausal status in women were included as covariates in survival models. 
TABLE 2: Number of participants defined as healthy or unhealthy by three definitions of metabolic health, and mortality rate in each group.

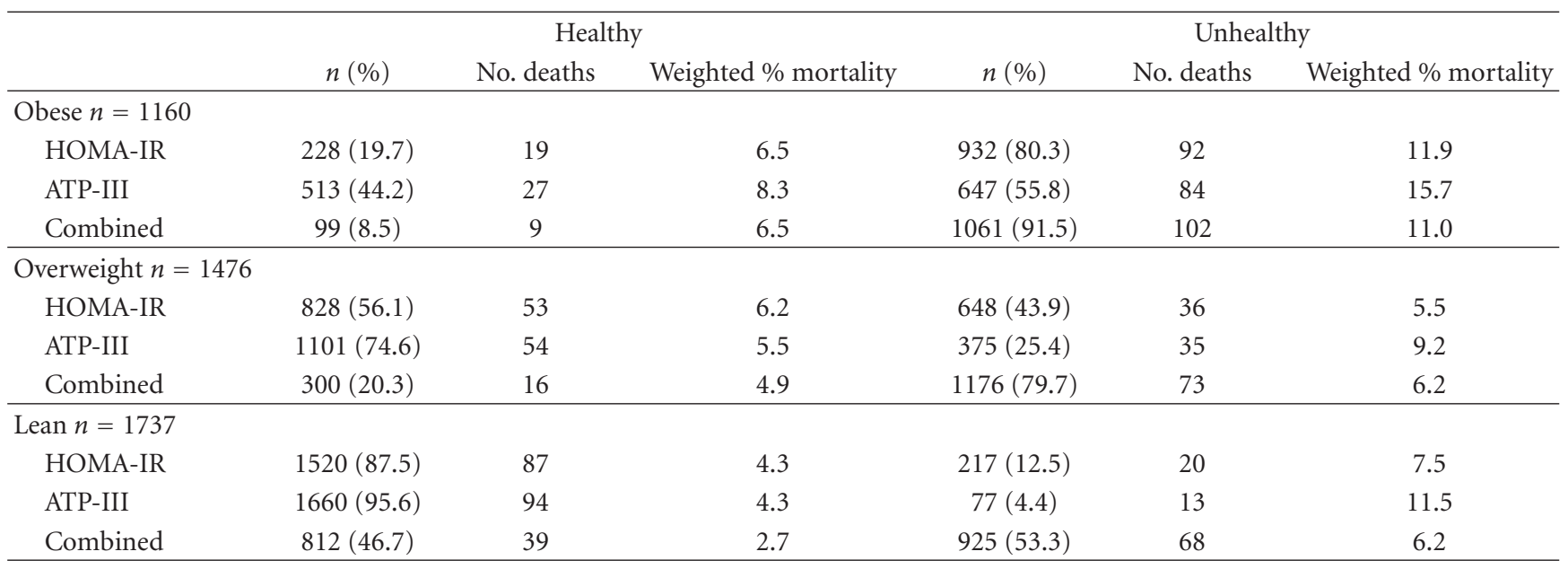

HOMA-IR: homeostasis model assessment-insulin resistance; ATP-III: Adult Treatment Panel III; $n$ (\%): unweighted number of participants defined as healthy or unhealthy by each definition within body mass index (BMI) group; number deaths: unweighted number of deaths per health and BMI status group by each definition; weighted $\%$ mortality: weighted percent of health and BMI group that is assumed deceased during follow-up period.

Differences in demographic variables between metabolic health-by-BMI categories were tested using proc survey reg for continuous variables and proc survey freq with the Roa-Scott modified chi-squared statistic for categorical variables. All analyses used appropriate sample weights as provided by the NCHS to account for the complex survey design of NHANES. All analyses were conducted using the Statistical Analysis System survey procedures (SAS version 9.3, 2011, Cary, NC, USA).

\section{Results}

3.1. Sample Description. The final sample of eligible participants $(n=4373)$ had a mean \pm standard deviation age of $37.1 \pm 10.9$ years, BMI $27.3 \pm 5.8 \mathrm{~kg} / \mathrm{m}^{2}$, and was $49.4 \%$ female. Of the 4373 participants included, 1737 were classified as lean (39.7\%), 1476 were overweight (33.8\%), and 1160 were obese $(26.5 \%)$, consistent with national trends in the US for BMI status. After an average of $175.8 \pm$ 29.4 months (14.7 years) of followup after the exam, 307 participants, or $7 \%$, were deceased (Table 2).

3.2. Comparison of MHO Samples by Different Definitions. The application of the three definitions of metabolic health resulted in different sample sizes within different metabolic health-by-BMI categories (Table 2). Furthermore, the amount of overlap in the sample of MHO individuals between definitions was low (Figure 1). Only 40 individuals with obesity (3.4\% of obese participants) were identified as healthy by all three definitions, and 207 (17.8\%) were healthy by at least two definitions. In contrast, 567 participants with obesity $(48.9 \%)$ were identified as unhealthy by all three definitions. It is important to note that $47.7 \%(n=553)$ of obese participants were classified both as unhealthy and healthy, depending on which definition was used.
3.3. Characterization of Health-by-BMI Groups. The different metabolic health-by-BMI groups had significantly different average ages, gender distribution, proportion of postmenopausal women, and race/ethnicity distribution (Table 3). In general, the lean groups, both healthy and unhealthy appeared to be younger than the obese or overweight groups.

Anthropometric and clinical characteristics are presented in Table 4. MHO participants had significantly higher BMI and WC than metabolically healthy overweight and lean groups by all three definitions. By the HOMA-IR definition, MHO participants had significantly lower BMI and WC than unhealthy obese individuals. This was also true of WC for the MHO participants when defined by ATP-III metabolic syndrome criteria.

In general, the MHO group had average levels of risk markers that were superior to the unhealthy groups, notably the unhealthy obese, but worse than the metabolically healthy lean groups. There was some variation in this pattern, depending on marker or health definition. For example, LDL-C was not significantly different between MHO and healthy lean groups by the combined definition. Similarly, there were no significant differences in TC or LDL-C between $\mathrm{MHO}$ and unhealthy obese when health was defined using the HOMA-IR cutoff.

3.4. All-Cause Mortality Risk in Metabolic Health-by-BMI Groups. HR and CI from the survival analysis are presented in Figure 2. Unhealthy obese individuals had higher HR compared to the healthy lean reference group, regardless of how metabolic health was defined (HOMA-IR HR 2.07 (CI 1.3-3.4), $P<0.01$; ATP-III HR 1.98 (CI 1.4-2.9), $P<$ 0.001; combined definition HR 2.19 (CI 1.3-3.8), $P<0.01$ ). The risk of all-cause mortality was not significantly higher in the MHO, healthy overweight, unhealthy overweight, or unhealthy lean groups compared to the healthy lean reference 


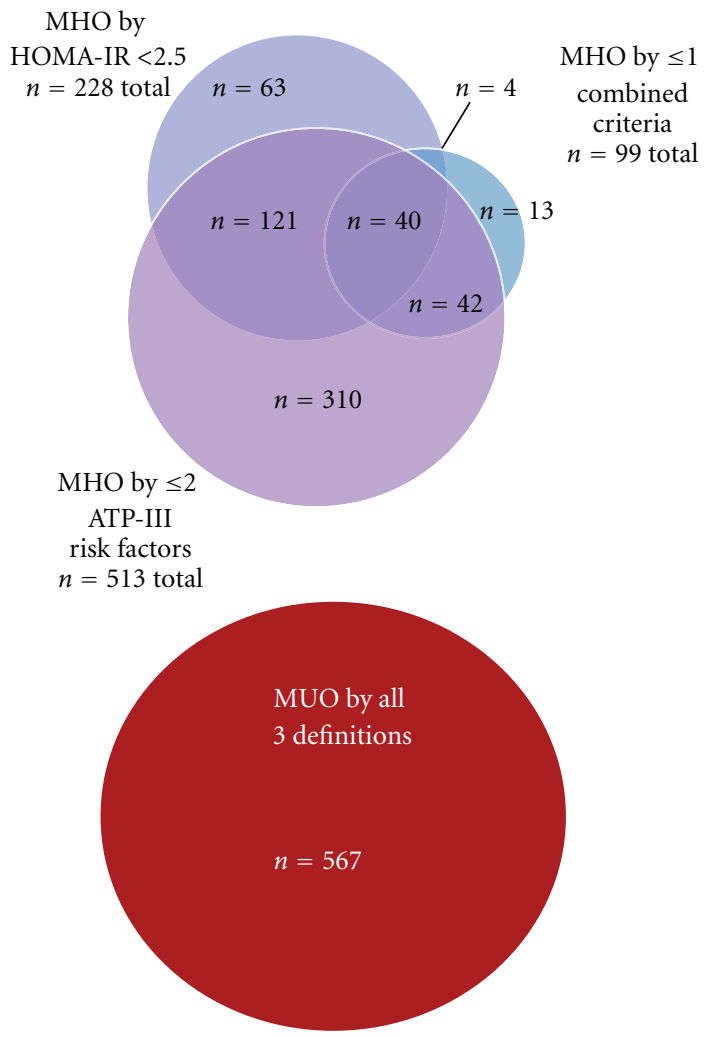

Figure 1: Overlap and uniquely classified obese individuals by three different metabolic health definitions. For the description of definitions of metabolic health, see Table 1. HOMA-IR, homeostasis model assessment-insulin resistance; ATP-III, Adult Treatment Panel III; MHO, metabolically healthy obese; MUO, metabolically unhealthy obese. Obese participants, $n=1160$.

group, again regardless of how metabolic health was defined (MHO HOMA-IR HR 1.42 (CI 0.6-3.2); MHO ATP-III HR 1.54 (CI 0.7-3.3); MHO Combined definition HR 1.48 (CI 0.5-4.2)) (Figure 2). However, when the MHO group was used as the reference group, resulting HRs were not significantly different from any of the other groups, including the metabolically unhealthy obese groups (data not shown).

\section{Discussion}

Results of the current study indicate that individuals with MHO do not have significantly increased risk of all-cause mortality over a followup of approximately 15 years. These results contrast with the findings of Kuk and Ardern [10] who used an earlier release of NHANES mortality data with approximately eight years of followup. Kuk and Ardern [10] reported an increased risk of all-cause mortality in individuals with $\mathrm{MHO}$, using slightly different definitions of metabolic health (HOMA-IR 2.5 and $<2$ ATP-III risk factors not including WC). Differences between the previous study [10] and current results may be attributed to the shorter follow-up time. The current study had a higher mortality prevalence of $7 \%$ compared to $5 \%$ previously reported [10], despite the fact that the sample chosen for the current analysis was younger at the time of survey. Furthermore, some evidence indicates that at least 10 years of followup data may be needed to detect the effect of metabolic syndrome on mortality rates [37]. Disparate findings are likely not attributable to analytical differences such as age range or covariates, as methods used by Kuk and Ardern [10] were applied to the newer dataset with similar findings as currently reported (data not shown). Current findings are consistent with Calori and colleagues [21] and Ortega and colleagues [22] in which no significant increases in mortality risk of $\mathrm{MHO}$ participants compared to healthy lean participants were found.

Although the MHO groups did not have HRs that were significantly greater than healthy lean reference groups, MHO groups did present with HR indicative of a higher likelihood of mortality. MHO individuals were not at significantly decreased risk of all-cause mortality compared to unhealthy obese individuals, suggesting an intermediate level of risk for $\mathrm{MHO}$ between healthy lean and unhealthy obese groups. Clinical characteristics (Table 4) support this idea, with values superior to those in the unhealthy obese group, but less optimal than individuals in the healthy lean group (i.e., the most healthy group). These findings are consistent with Marini and colleagues [12] who found that MHO participants had an intermediate CVD risk profile between healthy nonobese and unhealthy obese participants.

Clinically, this indicates that weight loss is likely the proper treatment outcome for obese individuals, regardless of health status. The appropriateness of weight loss as a treatment for MHO individuals has been questioned [38, 39]. Indeed, several studies have shown no improvement in the health profile of $\mathrm{MHO}$ individuals after weight loss $[35,40,41]$, and one study has shown a deterioration in insulin resistance after diet-induced weight loss in postmenopausal women [38]. However, two other studies have shown small but significant improvements in health markers after weight loss in $\mathrm{MHO}$ individuals [42, 43]. Arguments against aggressively pursuing weight loss in $\mathrm{MHO}$ individuals include the chance of harm [38], ineffectiveness of weightloss interventions over the long term [44], and adverse effects of weight cycling $[45,46]$. Future studies should attempt to clarify the effect of weight loss in this population, as disease may simply be delayed in $\mathrm{MHO}$ individuals.

In the current study, metabolically healthy groups were significantly younger than unhealthy groups, suggesting shorter duration of obesity. This finding agrees with previous studies [33, 36, 47-49], although most reports of MHO do not find significant differences in age between healthy and unhealthy obese groups $[3,12,13,15,19,34,35$, $38,41,43,50-64]$. A few studies have even documented significantly older MHO groups $[21,42,65]$. In a young, male, Korean sample, Chang and colleagues [66] found that $\mathrm{MHO}$ individuals were more likely than lean controls to develop metabolic abnormalities or disease precursors over five years of observation. This suggests that BMI, rather than age, is the key determinant of metabolic health. Yet, when Chang and colleagues [66] further examined differences between MHO participants who did or did not prospectively develop metabolic abnormalities, they found 


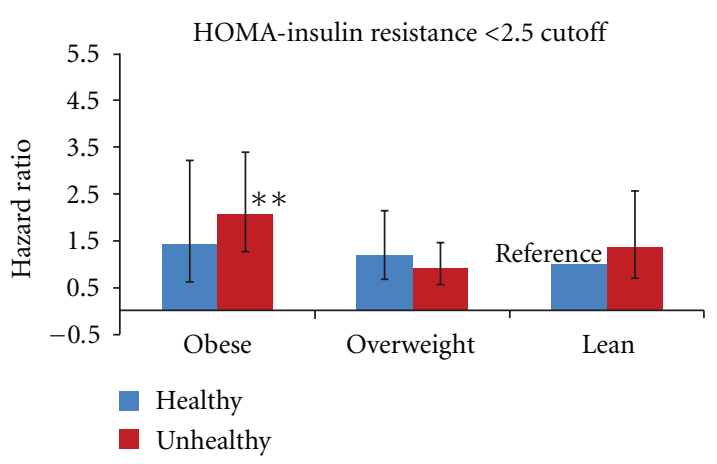

(a)

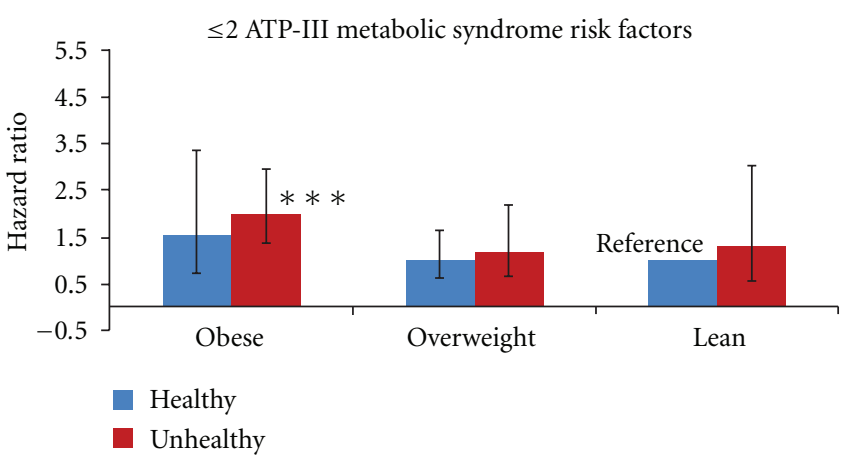

(b)

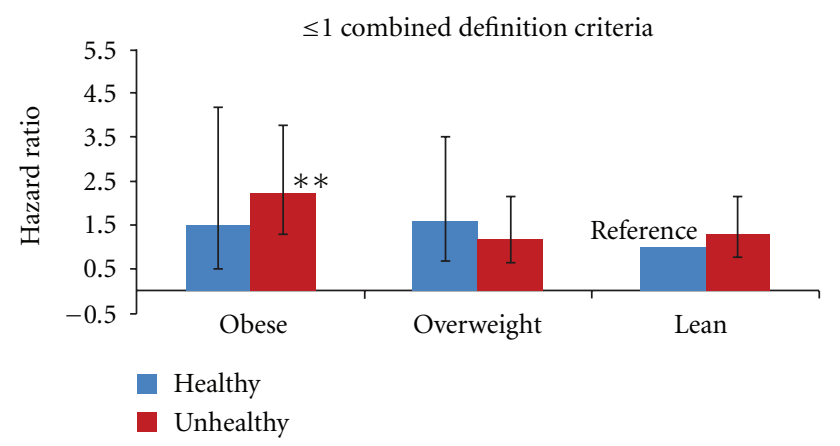

(c)

Figure 2: Risk of Mortality Associated with Metabolic Health and Body Mass Index (BMI) by Three Definitions. Error bars represent 95\% confidence intervals of hazard ratios. *** Significant difference from reference group (lean healthy) at $P \leq 0.001$; ** significant difference from reference group (lean healthy) at $P \leq 0.01$; data analyzed using Cox Survival Analysis, adjusting for sex, age, income, education, race/ethnicity, smoking status, alcohol consumption, marital status, leisure time physical activity, and menopausal status. For description of definitions of metabolic health, see Table 1. HOMA-IR, homeostasis model assessment-insulin resistance; ATP-III, Adult Treatment Panel III.

that individuals who remained metabolically healthy were significantly younger. Future longitudinal studies should explore duration of obesity as a possible explanation for the MHO phenotype.

The three different definitions of metabolic health applied to the current sample had very low rates of agreement, with less than $4 \%$ of obese participants classified as healthy by all three definitions. Furthermore, there was little overlap between definitions, and the clinical profile differed depending on definition used. These results provide some insights into the ambiguous nature of previous results, as inconsistencies in the literature may be due to the application of unique definitions of metabolic health. However, the hypothesis that mortality risk of MHO would be dependent upon definition of metabolic health used was not supported by results of the current analysis. Despite the fact that each definition identified different participants as healthy, results from this survival analysis were surprisingly similar-MHO participants by each definition were not at significantly increased risk of mortality compared to healthy lean individuals.

Potential mechanisms of protection from disease and mortality in $\mathrm{MHO}$ are the focus of a growing body of literature. One potential explanation is that MHO individuals are better able to handle excess calories in a healthful way by storing them as subcutaneous fat or using them as energy. Despite having comparable BMI and percent body fat, $\mathrm{MHO}$ individuals have much less visceral fat than metabolically unhealthy obese individuals $[51,56,67]$. McLaughlin and colleagues [3] showed that subcutaneous adipose tissue from MHO individuals had higher levels of adipose cell differentiation markers when compared to unhealthy obese participants, suggesting that metabolically unhealthy obese individuals may have impaired subcutaneous adipogenesis. Several studies have shown that visceral adipocytes from MHO individuals are smaller than those from metabolically unhealthy individuals $[36,56,61]$.

Some evidence indicates that liver fat accumulation may be the underlying factor in metabolic disturbances traditionally associated with obesity. Indeed, several recent studies have shown that liver fat content is linked to metabolic complications independent of overall body fat content [68] or even visceral fat levels $[69,70]$. Previous studies have shown that MHO individuals have lower levels of liver fat measured by magnetic resonance imaging $[13,56]$ or estimated by the Fatty Liver Index [58] compared to metabolically unhealthy obese individuals. Kantartzis and colleagues [71] showed that liver fat more than visceral fat determined the severity of prediabetes. In the Cremona Cohort, liver fat by the Fatty Liver Index was associated 
TABle 3: Demographic characteristics by metabolic health and body mass index category.

\begin{tabular}{|c|c|c|c|c|c|c|c|c|}
\hline & \multirow{2}{*}{ Definition } & \multicolumn{3}{|c|}{ Healthy } & \multicolumn{3}{|c|}{ Unhealthy } & \multirow{2}{*}{$P$} \\
\hline & & Obese & Overwt & Lean & Obese & Overwt & Lean & \\
\hline \multirow{3}{*}{ Age years, weighted mean (SEM) } & HOMA-IR & $38.9(1.3)$ & $38.3(0.5)$ & $35.0(0.4)$ & $41.0(0.5)$ & $40.3(0.7)$ & $37.4(1.2)$ & $<0.0001$ \\
\hline & ATP-III & $37.1(0.6)$ & $37.2(0.4)$ & $34.8(0.4)$ & $42.8(0.6)$ & $44.7(0.7)$ & $42.1(1.4)$ & $<0.0001$ \\
\hline & Combined & $38.6(2.1)$ & $35.1(0.7)$ & $32.3(0.4)$ & $40.7(0.5)$ & $40.0(0.5)$ & $37.7(0.6)$ & $<0.0001$ \\
\hline \multirow{9}{*}{ Sex, weighted \% } & HOMA-IR & & & & & & & \multirow{3}{*}{$<0.0001$} \\
\hline & Male & 38.3 & 61.2 & 44.7 & 47.3 & 61.3 & 55.1 & \\
\hline & Female & 60.7 & 38.8 & 55.3 & 52.7 & 38.7 & 44.9 & \\
\hline & ATP-III & & & & & & & \multirow{3}{*}{$<0.0001$} \\
\hline & Male & 34.2 & 62.0 & 45.0 & 53.1 & 59.0 & 56.2 & \\
\hline & Female & 65.8 & 38.0 & 55.0 & 46.9 & 41.0 & 43.8 & \\
\hline & Combined & & & & & & & \multirow{3}{*}{$<0.0001$} \\
\hline & Male & 43.8 & 53.1 & 42.4 & 45.8 & 63.3 & 48.5 & \\
\hline & Female & 56.2 & 46.9 & 57.6 & 54.2 & 36.7 & 51.5 & \\
\hline \multirow{3}{*}{$\begin{array}{l}\text { Menopause, weighted \% of females with } \\
\text { menopause }\end{array}$} & HOMA-IR & 30.2 & 28.7 & 15.6 & 31.6 & 30.0 & 21.3 & 0.0002 \\
\hline & ATP-III & 23.3 & 22.5 & 14.3 & 38.6 & 49.4 & 60.4 & $<0.0001$ \\
\hline & Combined & 27.2 & 15.3 & 9.7 & 31.6 & 33.6 & 22.4 & 0.0001 \\
\hline \multirow{15}{*}{ Race/ethnicity, weighted \% } & HOMA-IR & & & & & & & \multirow{5}{*}{$<0.0001$} \\
\hline & NHW & 72.8 & 77.5 & 80.2 & 69.2 & 66.5 & 63.3 & \\
\hline & NHB & 15.7 & 9.8 & 8.0 & 14.2 & 13.9 & 14.4 & \\
\hline & MA & 5.4 & 5.3 & 4.2 & 7.9 & 10.6 & 7.9 & \\
\hline & Other & 6.1 & 7.4 & 7.6 & 8.8 & 9.0 & 14.1 & \\
\hline & ATP-III & & & & & & & \multirow{5}{*}{$<0.0001$} \\
\hline & NHW & 62.1 & 72.9 & 78.6 & 75 & 76.3 & 82.6 & \\
\hline & NHB & 20.5 & 12.3 & 8.7 & 10.6 & 7.6 & 6.6 & \\
\hline & MA & 7.3 & 6.8 & 4.5 & 7.3 & 8.3 & 3.3 & \\
\hline & Other & 10.1 & 8.0 & 8.2 & 7.0 & 7.9 & 7.5 & \\
\hline & Combined & & & & & & & \multirow{5}{*}{$<0.0001$} \\
\hline & NHW & 49.2 & 73.1 & 78.2 & 71.5 & 73.8 & 79.4 & \\
\hline & NHB & 31.2 & 14.2 & 9.1 & 13.2 & 10.4 & 8.1 & \\
\hline & MA & 6.2 & 7.6 & 4.8 & 7.4 & 7.1 & 4.2 & \\
\hline & Other & 13.4 & 5.0 & 7.9 & 7.8 & 8.7 & 8.3 & \\
\hline
\end{tabular}

Overwt: overweight; HOMA-IR: homeostasis model assessment-insulin resistance; ATP-III: Adult Treatment Panel III; SEM: standard error of the mean; NHW: non-Hispanic white; NHB: non-Hispanic black; MA: Mexican American. Data analyzed using SAS survey regression procedure (continuous) or survey frequency procedure (categorical). $P$ values indicate significant differences between metabolic health and body mass index categories within definitions.

with all cause, CVD, and cancer mortality rates, although this association was linked to insulin resistance [72]. Lower levels of intramuscular fat also may contribute to the MHO profile, as Perseghin and colleagues [73] have shown that intramuscular fat is a determinant of insulin resistance. Studies have shown lower levels of intramuscular fat in MHO individuals compared to unhealthy obese individuals $[13,71]$ and similar levels to healthy lean participants [13]. However, other studies have failed to find any difference $[51,55,62]$.

Another related potential explanation for the lower risk of mortality in $\mathrm{MHO}$ is the favorable inflammatory milieu with which these individuals present. Although obesity is generally associated with a chronic inflammatory state, this is not absolute in MHO individuals. MHO individuals have been found to have lower levels of circulating inflammatory markers $[35,55]$, higher levels of circulating anti-inflammatory natural killer cells and cytotoxic $\mathrm{T}$ lymphocytes [60], decreased macrophage infiltration into visceral adiposity [56], and decreased activation of certain proinflammatory pathways in visceral adipose tissue [70] compared to metabolically unhealthy individuals. This favorable inflammatory milieu may reflect normal or healthy circulating levels of the anti-inflammatory adipokine and adiponectin. A consistent finding in the MHO literature is that metabolically healthy obese individuals have normal or even elevated adiponectin levels compared to lean controls $[34,56,67,74]$. Stefan and colleagues [75] identified a single nucleotide polymorphism in the adiponectin receptor 1 (ADIPOR1) gene, which has been shown to be associated 
TABLE 4: Anthropometric and clinical characteristics by metabolic health and body mass index category shown as weighted mean (SEM).

\begin{tabular}{|c|c|c|c|c|c|c|c|}
\hline & \multirow{2}{*}{ Definition } & \multicolumn{3}{|c|}{ Healthy } & \multicolumn{3}{|c|}{ Unhealthy } \\
\hline & & Obese & Overwt & Lean & Obese & Overwt & Lean \\
\hline \multirow{3}{*}{ BMI, kg/m² } & HOMA-IR & $33.3(0.3)$ & $26.9(0.1)^{*}$ & $22.1(0.1)^{*}$ & $35.1(0.2)^{*}$ & $27.5(0.1)^{*}$ & $23.0(0.2)^{*}$ \\
\hline & ATP-III & $34.1(0.3)$ & $26.9(0.1)^{*}$ & $22.1(0.1)^{*}$ & $35.1(0.2)$ & $27.8(0.1)^{*}$ & $23.2(0.2)^{*}$ \\
\hline & Combined & $34.3(0.5)$ & $26.9(0.2)^{*}$ & $21.8(0.07)^{*}$ & $34.8(0.2)$ & $27.1(0.08)^{*}$ & $22.5(0.08)^{*}$ \\
\hline \multirow{3}{*}{ Waist circumference, $\mathrm{cm}$} & HOMA-IR & $104.8(0.7)$ & $92.4(0.4)^{*}$ & $79.4(0.3)^{*}$ & $110.9(0.5)^{*}$ & $95.7(0.6)^{*}$ & $84.5(0.8)^{*}$ \\
\hline & ATP-III & $105.7(0.8)$ & $92.1(0.3)^{*}$ & $79.5(0.3)^{*}$ & $112.2(0.6)^{*}$ & $98.5(0.6)^{*}$ & $86.7(0.5)^{*}$ \\
\hline & Combined & $107.2(1.5)$ & $90.5(0.8)^{*}$ & $77.6(0.3)^{*}$ & $109.8(0.5)$ & $94.4(0.4)^{*}$ & $81.8(0.4)^{*}$ \\
\hline \multirow{3}{*}{ HOMA-IR } & HOMA-IR & $1.9(0.04)$ & $1.8(0.03)^{\dagger}$ & $1.5(0.02)^{*}$ & $5.7(0.3)^{*}$ & $3.8(0.09)^{*}$ & $3.2(0.05)^{*}$ \\
\hline & ATP-III & $3.2(0.1)$ & $2.2(0.05)^{*}$ & $1.6(0.03)^{*}$ & $6.0(0.3)^{*}$ & $3.5(0.1)$ & $2.5(0.1)^{\dagger}$ \\
\hline & Combined & $3.1(0.3)$ & $1.8(0.06)^{\dagger}$ & $1.4(0.03)^{*}$ & $5.0(0.2)^{*}$ & $2.6(0.06)$ & $1.8(0.03)^{\dagger}$ \\
\hline \multirow{3}{*}{ Glucose, $\mathrm{mmol} / \mathrm{L}$} & HOMA-IR & $5.2(0.05)$ & $5.2(0.03)$ & $5.0(0.02)^{*}$ & $6.2(0.1)^{*}$ & $5.9(0.09)^{*}$ & $5.8(0.1)^{\dagger}$ \\
\hline & ATP-III & $5.3(0.03)$ & $5.2(0.03)$ & $5.1(0.01)^{*}$ & $6.5(0.1)^{*}$ & $6.0(0.1)^{*}$ & $6.0(0.2)^{\ddagger}$ \\
\hline & Combined & $5.6(0.3)$ & $5.1(0.04)$ & $5.0(0.02)^{*}$ & $6.0(0.08)$ & $5.5(0.04)$ & $5.2(0.03)$ \\
\hline \multirow{3}{*}{ HDL-C, mmol/L } & HOMA-IR & $1.3(0.04)$ & $1.3(0.02)$ & $1.4(0.02)^{*}$ & $1.1(0.02)^{*}$ & $1.1(0.02)^{\dagger}$ & $1.2(0.03)$ \\
\hline & ATP-III & $1.3(0.02)$ & $1.3(0.02)$ & $1.4(0.02)^{*}$ & $1.0(0.02)^{*}$ & $1.0(0.02)^{*}$ & $1.1(0.05)^{*}$ \\
\hline & Combined & $1.4(0.05)$ & $1.4(0.02)$ & $1.5(0.02)$ & $1.1(0.02)^{*}$ & $1.2(0.02)^{*}$ & $1.3(0.02)^{\S}$ \\
\hline \multirow{3}{*}{ Triglycerides, $\mathrm{mmol} / \mathrm{L}$} & HOMA-IR & $1.4(0.07)$ & $1.4(0.06)$ & $1.1(0.03)^{*}$ & $2.2(0.1)^{*}$ & $1.9(0.08)^{*}$ & $1.6(0.08)$ \\
\hline & ATP-III & $1.2(0.03)$ & $1.3(0.04)^{\ddagger}$ & $1.1(0.02)^{\dagger}$ & $2.5(0.2)^{*}$ & $2.3(0.1)^{*}$ & $2.6(0.2)^{*}$ \\
\hline & Combined & $1.0(0.04)$ & $0.9(0.03)$ & $0.8(0.02)^{\ddagger}$ & $2.1(0.1)^{*}$ & $1.7(0.05)^{*}$ & $1.4(0.04)^{*}$ \\
\hline \multirow{3}{*}{ Total cholesterol, mmol/L } & HOMA-IR & $5.4(0.1)$ & $5.2(0.04)$ & $4.9(0.03)^{\dagger}$ & $5.4(0.05)$ & $5.4(0.06)$ & $5.2(0.1)$ \\
\hline & ATP-III & $5.1(0.06)$ & $5.1(0.04)$ & $4.9(0.03)^{\dagger}$ & $5.6(0.07)^{*}$ & $5.6(0.08)^{*}$ & $5.7(0.2)^{\ddagger}$ \\
\hline & Combined & $4.2(0.1)$ & $4.2(0.04)$ & $4.3(0.03)$ & $5.5(0.05)^{*}$ & $5.5(0.04)^{*}$ & $5.5(0.04)^{*}$ \\
\hline \multirow{3}{*}{$\mathrm{LDL}^{-\mathrm{C}^{\mathrm{a}}}, \mathrm{mmol} / \mathrm{L}$} & HOMA-IR & $3.5(0.1)$ & $3.3(0.04)$ & $3.0(0.03)^{*}$ & $3.4(0.05)$ & $3.4(0.05)$ & $3.3(0.1)$ \\
\hline & ATP-III & $3.3(0.06)$ & $3.3(0.03)$ & $3.0(0.03)^{*}$ & $3.6(0.05)^{\ddagger}$ & $3.6(0.07)^{\ddagger}$ & $3.5(0.05)$ \\
\hline & Combined & $2.3(0.1)$ & $2.4(0.03)$ & $2.4(0.02)$ & $3.5(0.04)^{*}$ & $3.6(0.03)^{*}$ & $3.5(0.04)^{*}$ \\
\hline \multirow{3}{*}{ Systolic BP, mmHg } & HOMA-IR & $120.2(1.4)$ & $117.6(0.6)$ & $113.0(0.4)^{*}$ & $124.7(0.6)^{\ddagger}$ & $121.2(0.9)$ & $117.6(1.1)$ \\
\hline & ATP-III & $117.0(0.6)$ & $116.8(0.5)$ & $112.8(0.4)^{*}$ & $128.1(0.8)^{*}$ & $125.8(1.3)^{*}$ & $124.5(1.7)^{\dagger}$ \\
\hline & Combined & $120.0(1.4)$ & $113.1(0.7)^{*}$ & $111.3(0.7)^{*}$ & $124.0(0.6)^{\ddagger}$ & $120.3(0.6)$ & $115.3(0.5)^{\ddagger}$ \\
\hline \multirow{3}{*}{ Diastolic BP, mmHg } & HOMA-IR & $75.8(1.2)$ & $74.3(0.5)$ & $70.5(0.4)^{*}$ & $79.5(0.5)^{\ddagger}$ & $77.4(0.7)$ & $74.3(1.0)$ \\
\hline & ATP-III & $74.2(0.6)$ & $74.0(0.5)$ & $70.4(0.3)^{*}$ & $81.7(0.6)^{*}$ & $80.0(0.6)^{*}$ & $79.1(1.4)^{\ddagger}$ \\
\hline & Combined & $73.3(1.8)$ & $72.3(0.7)^{\S}$ & $69.6(0.4)$ & $79.2(0.5)^{\ddagger}$ & $76.2(0.4)$ & $72.0(0.5)$ \\
\hline
\end{tabular}

Overwt: overweight; BMI: body mass index; HOMA-IR: homeostasis model assessment-insulin resistance; ATP-III: Adult Treatment Panel III; SEM: standard error of the mean; HDL-C: high density lipoprotein cholesterol; LDL-C: low density lipoprotein cholesterol; BP: blood pressure. All variables measured in the morning after an overnight fast of $\geq 6$ hours, except for LDL-C which was calculated using the Friedewald formula. Data analyzed using SAS survey regression procedure (continuous) or survey frequency procedure (categorical). ${ }^{a} \mathrm{LDL}$ missing for $n=91$ participants, ${ }^{*} P \leq 0.0001,{ }^{\dagger} P \leq 0.001,{ }^{\ddagger} P \leq 0.01$, and ${ }^{\S} P \leq$ 0.05 significantly different from metabolically healthy obese by the same definition.

with higher liver fat content and lower insulin sensitivity, suggesting a possible mechanism for adiponectin signaling in the MHO condition.

Overall, current findings indicate that $\mathrm{MHO}$ individuals have an intermediate health profile that is more healthy than other obese adults classified as unhealthy but less healthy than adults with lower BMI and categorized as healthy. Several researchers have questioned the use of the term $\mathrm{MHO}$ or metabolically normal obesity, due to the potential diminishment of public understanding of the serious risks associated with obesity $[76,77]$. As seen here (Table 4 ) and in another analysis [9], the clinical profile of MHO participants depends on the definition used to denote health. As one example, $\mathrm{MHO}$ adults in the current study, as defined by both the HOMA-IR and ATP-III definitions, show average LDL-C levels above the recommended $2.6 \mathrm{mmol} / \mathrm{L}$, while only the Combined definition, which includes LCL-C as a criterion, results in LDL-C within the normal range. Other studies have shown that even when average levels of health markers are normal, anywhere from 7 to $51 \%$ of participants classified as MHO have elevated levels of the same health markers $[8,14,48,53]$. In summary, results presented here indicate that a very small percentage of obese participants $(\sim 4 \%)$ are healthy by every metabolic health criteria that might be considered, returning to the question of which definition of metabolic health should be used.

Several investigators have advocated for an expert panel to form a consensus definition of $\mathrm{MHO}$ for use in future 
research and practice $[24,78]$. Such a definition would lead to a more cohesive and easily understood body of literature on which to base practice. However, this also would implicitly favor the notion of $\mathrm{MHO}$ being a distinct profile over the idea of health as a continuum. Findings presented here, namely, the disagreement of classification between definitions and variability of metabolic health profile depending on criteria included, seem to support the concept of several related yet separate health continuums (i.e., insulin resistance, hyperlipidemia, hypertension, etc.) rather than a unified and unique subgroup [79]. However, even if a biologically distinct subset of obese individuals protected from all chronic disease risk associated with obesity does not exist, this area of research still has merit. From a societal view, this research is important because it increases awareness that obesity is associated with a variety of health parameters, challenging assumptions and biases. The paradigm of comparing individuals with disparate metabolic health profiles despite equal total adiposity will help in the understanding of mechanisms connecting adiposity to health. Research into MHO has already made important contributions to the relationships among health, weight, and disease, providing evidence that supports theories generated from animal studies [80].

Several limitations of the current study exist. This analysis is limited by the cross-sectional design for physical data. Although participants were classified according to their health and BMI status at baseline, no data were available regarding weight changes during the $\sim 15$ years of followup. It is possible that weight change(s), rather than weight status at time of data collection, impact(s) mortality risk most profoundly. Assuming that $\mathrm{MHO}$ is an earlier stage of obesity-related disease progression, it could be argued that participants who were obese yet still healthy at the time of data collection were most likely to lose weight and maintain that weight loss during the follow-up period, which would have maintained health status, thereby reducing risk of mortality. In contrast, assuming that $\mathrm{MHO}$ is protective against disease risk, it is equally plausible that individuals with obesity were much more likely to undergo periods of weight cycling which could falsely elevate their risk of mortality [46]. Ultimately, detailed longitudinal data are needed to separate influences of weight gain, weight loss, and weight cycling on mortality risk of individuals with different metabolic health designations. Another important area for future research is investigation into additional variables (e.g., fitness and diet) that may explain differences in HR between health status and BMI groups. Another limitation is the use of BMI to define adiposity. A recent meta-analysis has shown that BMI cutoff values misclassify $50 \%$ of individuals with elevated body fat percentage [81]. However, the use of BMI is prevalent in the MHO literature and in clinical practice, allowing comparison and interpretation of current results. A related issue of interest is whether to include WC as a part of metabolic syndrome criteria used to define MHO. Several investigators have chosen to exclude WC when defining $\mathrm{MHO}$, because of the strong positive association between WC and BMI and inability of WC to differentiate between visceral and subcutaneous fat $[10,22,24,60,61]$. However, when excluding WC, the number of criteria allowed in the healthy definition has been lowered from $\leq 2$ to $\leq 1$, resulting in similar samples of MHO between methods. Excluding WC may lead to the misclassification of metabolically unhealthy lean participants as healthy, presenting bias. Lee and colleagues [82] concluded that the waist to hip ratio, rather than BMI or WC, was most salient for the identification of $\mathrm{MHO}$ and metabolically unhealthy lean individuals. Such results are intriguing and need to be further explored. Lastly, because insulin measurements lack standardization across assays [83, 84], HOMA-IR values should be cautiously interpreted and compared. The current analysis used a cutoff of 2.5 for comparison to the work of Kuk and Ardern [10]; this cutoff may not be appropriate for other studies.

Strengths of the current study include the use of a nationally representative sample of the US population, robust end point (all-cause mortality), and a relatively long followup period ( $\sim 15$ years). NHANES data provides measured rather than self-reported weight and height. Blood collection and processing are standardized and use appropriate quality controls. Additionally, by comparing and contrasting several definitions of metabolic health, this study provides unique insight into the consequences of using varying definitions of MHO.

It is important to note that even if individuals with $\mathrm{MHO}$ are not at increased risk for all-cause mortality, they are still at risk for other complications of obesity such as osteoarthritis [85], poorer functional ability [50], lower quality of life, higher perceived stress, lower self-esteem, and poorer body image [86]. Individuals with $\mathrm{MHO}$ are also subject to the same social stigma to which metabolically unhealthy obese individuals are resulting in increased stress, risk of psychological disorders, substandard health care, and decreased health care utilization [87]. Ironically, the basis for weight stigmatization is related, in part, to the negative health effects and medical costs supposedly associated with obesity. These additional factors require further evaluation that is beyond the scope of the current study.

\section{Conclusions}

In summary, these results indicate that $\mathrm{MHO}$ adults may present with an intermediate risk profile for all-cause mortality. From a clinical perspective, this suggests that weight loss is an appropriate treatment outcome, even in healthy obese individuals. Further, this study shows that whether an individual is identified as $\mathrm{MHO}$ is dependent upon the definition of metabolic health used, with little overlap between definitions. It is essential to carefully consider options for the definition of $\mathrm{MHO}$, and a consensus definition for $\mathrm{MHO}$ is needed. Finally, the MHO phenotype holds promise for understanding mechanisms that link excess adiposity to morbidity and mortality.

\section{Conflict of Interests}

The senior author discloses research funding from General Mills Bell Institute of Health and Nutrition, The Center 
for Nutrition and Health, The Hershey Company, Dairy Research Institute, and the United States Department of Agriculture.

\section{Acknowledgment}

Graduate Research Assistant support was provided to C. M. Durward by General Mills Bell Institute of Health and Nutrition.

\section{References}

[1] G. A. Bray, "Risks of obesity," Endocrinology and Metabolism Clinics of North America, vol. 32, no. 4, pp. 787-804, 2003.

[2] G. A. Bray, "Medical consequences of obesity," Journal of Clinical Endocrinology and Metabolism, vol. 89, no. 6, pp. 2583-2589, 2004.

[3] T. McLaughlin, A. Sherman, P. Tsao et al., "Enhanced proportion of small adipose cells in insulin-resistant vs insulinsensitive obese individuals implicates impaired adipogenesis," Diabetologia, vol. 50, no. 8, pp. 1707-1715, 2007.

[4] V. Primeau, L. Coderre, A. D. Karelis et al., "Characterizing the profile of obese patients who are metabolically healthy," International Journal of Obesity, vol. 35, no. 7, pp. 971-981, 2011.

[5] M. Blüher, "The distinction of metabolically "healthy" from "unhealthy" obese individuals," Current Opinion in Lipidology, vol. 21, no. 1, pp. 38-43, 2010.

[6] E. Succurro, M. A. Marini, S. Frontoni et al., "Insulin secretion in metabolically obese, but normal weight, and in metabolically healthy but obese individuals," Obesity, vol. 16, no. 8, pp. 1881-1886, 2008.

[7] A. D. Karelis, D. H. St-Pierre, F. Conus, R. Rabasa-Lhoret, and E. T. Poehlman, "Metabolic and body composition factors in subgroups of obesity: What do we know?" Journal of Clinical Endocrinology and Metabolism, vol. 89, no. 6, pp. 2569-2575, 2004.

[8] R. P. Wildman, P. Muntner, K. Reynolds et al., "The obese without cardiometabolic risk factor clustering and the normal weight with cardiometabolic risk factor clustering: prevalence and correlates of 2 phenotypes among the US population (NHANES 1999-2004)," Archives of Internal Medicine, vol. 168, no. 15, pp. 1617-1624, 2008.

[9] P. Manu, C. Ionescu-Tirgoviste, J. Tsang, B. A. Napolitano, M. L. Lesser, and C. U. Correll, "Dysmetabolic signals in "metabolically healthy" obesity," Obesity Research and Clinical Practice, vol. 6, no. 1, pp. e9-e20, 2012.

[10] J. L. Kuk and C. I. Ardern, "Are metabolically normal but obese individuals at lower risk for all-cause mortality?" Diabetes Care, vol. 32, no. 12, pp. 2297-2299, 2009.

[11] G. A. Bray, M. B. Clearfield, D. J. Fintel, and D. S. Nelinson, "Overweight and obesity: the pathogenesis of cardiometabolic risk," Clinical Cornerstone, vol. 9, no. 4, pp. 30-42, 2009.

[12] M. A. Marini, E. Succurro, S. Frontoni et al., "Metabolically healthy but obese women have an intermediate cardiovascular risk profile between healthy nonobese women and obese insulin-resistant women," Diabetes Care, vol. 30, no. 8, pp. 2145-2147, 2007.

[13] N. Stefan, K. Kantartzis, J. Machann et al., "Identification and characterization of metabolically benign obesity in humans," Archives of Internal Medicine, vol. 168, no. 15, pp. 1609-1616, 2008.
[14] J. B. Meigs, P. W. F. Wilson, C. S. Fox et al., "Body mass index, metabolic syndrome, and risk of type 2 diabetes or cardiovascular disease," Journal of Clinical Endocrinology and Metabolism, vol. 91, no. 8, pp. 2906-2912, 2006.

[15] A. C. St-Pierre, B. Cantin, P. Mauriège et al., "Insulin resistance syndrome, body mass index and the risk of ischemic heart disease," Canadian Medical Association Journal, vol. 172, no. 10, pp. 1301-1305, 2005.

[16] F. Hosseinpanah, M. Barzin, F. Sheikholeslami, and F. Azizi, "Effect of different obesity phenotypes on cardiovascular events in Tehran lipid and glucose study (TLGS)," American Journal of Cardiology, vol. 107, no. 3, pp. 412-416, 2011.

[17] C. Voulgari, N. Tentolouris, P. Dilaveris, D. Tousoulis, N. Katsilambros, and C. Stefanadis, "Increased heart failure risk in normal-weight people with metabolic syndrome compared with metabolically healthy obese individuals," Journal of the American College of Cardiology, vol. 58, no. 13, pp. 1343-1350, 2011.

[18] K. E. Kip, O. C. Marroquin, D. E. Kelley et al., "Clinical importance of obesity versus the metabolic syndrome in cardiovascular risk in women: a report from the Women's Ischemia Syndrome Evaluation (WISE) study," Circulation, vol. 109, no. 6, pp. 706-713, 2004.

[19] J. Ärnlöv, E. Ingelsson, J. Sundström, and L. Lind, "Impact of body mass index and the metabolic syndrome on the risk of cardiovascular disease and death in middle-aged men," Circulation, vol. 121, no. 2, pp. 230-236, 2010.

[20] N. Stefan, A. Fritsche, and H. U. Häring, "Letter by Stefan et al regarding article, impact of body mass index and the metabolic syndrome on the risk of cardiovascular disease and death in middle-aged men," Circulation, vol. 122, no. 11, p. e456, 2010.

[21] G. Calori, G. Lattuada, L. Piemonti et al., "Prevalence, metabolic features, and prognosis of metabolically healthy obese italian individuals: the cremona study," Diabetes Care, vol. 34, no. 1, pp. 210-215, 2011.

[22] F. B. Ortega, D. C. Lee, P. T. Katzmarzyk et al., "The intriguing metabolically healthy but obesephenotype: cardiovascular prognosis and role of fitness," European Heart Journal. In press.

[23] C. Mason, P. T. Katzmarzyk, and S. N. Blair, "Eligibility for obesity treatment and risk of mortality in men," Obesity Research, vol. 13, no. 10, pp. 1803-1809, 2005.

[24] V. Messier, A. D. Karelis, D. Prud'Homme, V. Primeau, M. Brochu, and R. Rabasa-Lhoret, "Identifying metabolically healthy but obese individuals in sedentary postmenopausal women," Obesity, vol. 18, no. 5, pp. 911-917, 2010.

[25] J. L. Shea, E. W. Randell, and G. Sun, "The prevalence of metabolically healthy obese subjects defined by BMI and dualenergy X-ray absorptiometry," Obesity, vol. 19, no. 3, pp. 624630, 2011.

[26] Z. Pataky, V. Makoundou, P. Nilsson et al., "Metabolic normality in overweight and obese subjects. Which parameters? Which risks?" International Journal of Obesity, vol. 35, pp. 1208-1215, 2011.

[27] "Plan and operation of the Third National Health and Nutrition Examination Survey, 1988-94. Series 1: program and collection procedures," Vital Health Statistics, vol. 1, no. 32, pp. 1-407, 1994.

[28] E. L. Richman and M. J. Stampfer, "Editorial comment: weight loss and mortality in the elderly: Separating cause and effect," Journal of Internal Medicine, vol. 268, no. 2, pp. 103-105, 2010.

[29] A. D. Karelis, M. Brochu, and R. Rabasa-Lhoret, "Can we identify metabolically healthy but obese individuals (MHO)?" Diabetes and Metabolism, vol. 30, no. 6, pp. 569-572, 2004. 
[30] "Obesity: preventing and managing the global epidemic. Report of a WHO consultation," World Health Organization Technical Report Series, vol. 894, pp. 1-253, 2000.

[31] W. T. Friedewald, R. I. Levy, and D. S. Fredrickson, "Estimation of the concentration of low-density lipoprotein cholesterol in plasma, without use of the preparative ultracentrifuge," Clinical Chemistry, vol. 18, no. 6, pp. 499-502, 1972.

[32] D. R. Matthews, J. P. Hosker, and A. S. Rudenski, "Homeostasis model assessment: insulin resistance and $\beta$-cell function from fasting plasma glucose and insulin concentrations in man," Diabetologia, vol. 28, no. 7, pp. 412-419, 1985.

[33] K. Lee, "Metabolically obese but normal weight (MONW) and metabolically healthy but obese (MHO) phenotypes in Koreans: characteristics and health behaviors," Asia Pacific Journal of Clinical Nutrition, vol. 18, no. 2, pp. 280-284, 2009.

[34] W. Bik, J. Ostrowski, A. Baranowska-Bik et al., "Adipokines and genetic factors in overweight or obese but metabolically healthy Polish women," Neuroendocrinology Letters, vol. 31, no. 4, pp. 497-506, 2010.

[35] M. J. Shin, Y. J. Hyun, O. Y. Kim, J. Y. Kim, Y. Jang, and J. H. Lee, "Weight loss effect on inflammation and LDL oxidation in metabolically healthy but obese (MHO) individuals: low inflammation and LDL oxidation in MHO women," International Journal of Obesity, vol. 30, no. 10, pp. 1529-1534, 2006.

[36] B. Srdić, E. Stokić, A. Korać, M. Ukropina, K. Veliĉkovi, and M. Breberina, "Morphological characteristics of abdominal adipose tissue in normal-weight and obese women of different metabolic profiles," Experimental and Clinical Endocrinology and Diabetes, vol. 118, no. 10, pp. 713-718, 2010.

[37] J. Sundström, U. Risérus, L. Byberg, B. Zethelius, H. Lithell, and L. Lind, "Clinical value of the metabolic syndrome for long term prediction of total and cardiovascular mortality: prospective, population based cohort study," British Medical Journal, vol. 332, no. 7546, pp. 878-881, 2006.

[38] A. D. Karelis, V. Messier, M. Brochu, and R. Rabasa-Lhoret, "Metabolically healthy but obese women: effect of an energyrestricted diet," Diabetologia, vol. 51, no. 9, pp. 1752-1754, 2008.

[39] G. Perseghin, "Is a nutritional therapeutic approach unsuitable for metabolically healthy but obese women?" Diabetologia, vol. 51, no. 9, pp. 1567-1569, 2008.

[40] K. Kantartzis, J. Machann, F. Schick et al., "Effects of a lifestyle intervention in metabolically benign and malign obesity," Diabetologia, vol. 54, no. 4, pp. 864-868, 2011.

[41] T. McLaughlin, F. Abbasi, C. Lamendola et al., "Differentiation between obesity and insulin resistance in the association with C-reactive protein," Circulation, vol. 106, no. 23, pp. 29082912, 2002.

[42] P. M. Janiszewski and R. Ross, "Effects of weight loss among metabolically healthy obese men and women," Diabetes Care, vol. 33, no. 9, pp. 1957-1959, 2010.

[43] G. Sesti, F. Folli, L. Perego, M. L. Hribal, and A. E. Pontiroli, "Effects of weight loss in metabolically healthy obese subjects after laparoscopic adjustable gastric banding and hypocaloric diet," PLoS One, vol. 6, no. 3, Article ID e17737, 2011.

[44] T. Mann, A. J. Tomiyama, E. Westling, A. M. Lew, B. Samuels, and J. Chatman, "Medicare's search for effective obesity treatments: diets are not the answer," American Psychologist, vol. 62, no. 3, pp. 220-233, 2007.

[45] S. Graci, G. Izzo, S. Savino et al., "Weight cycling and cardiovascular risk factors in obesity," International Journal of Obesity, vol. 28, no. 1, pp. 65-71, 2004.
[46] S. N. Blair, J. Shaten, K. Brownell, G. Collins, and L. Lissner, "Body weight change, all-cause mortality, and cause-specific mortality in the multiple risk factor intervention trial," Annals of Internal Medicine, vol. 119, no. 7, part 2, pp. 749-757, 1993.

[47] R. Cherqaoui, T. A. Kassim, J. Kwagyan et al., "The metabolically healthy but obese phenotype in African Americans," Journal of Clinical Hypertension, vol. 14, no. 2, pp. 92-96, 2012.

[48] U. I. Khan, D. Wang, R. C. Thurston et al., "Burden of subclinical cardiovascular disease in "metabolically benign" and "at-risk" overweight and obese women: the Study of Women's Health Across the Nation (SWAN)," Atherosclerosis, vol. 217, no. 1, pp. 179-186, 2011.

[49] G. Sesti, E. Succurro, F. Arturi et al., "IGF-1 levels link estimated glomerular filtration rate to insulin resistance in obesity: a study in obese, but metabolically healthy, subjects and obese, insulin-resistant subjects," Nutrition, Metabolism and Cardiovascular Diseases, vol. 21, no. 12, pp. 933-940, 2010.

[50] D. R. Bouchard, M. F. Langlois, M. Brochu, I. J. Dionne, and J. P. Baillargeon, "Metabolically healthy obese women and functional capacity," Metabolic Syndrome and Related Disorders, vol. 9, no. 3, pp. 225-229, 2011.

[51] M. Brochu, A. Tchernof, I. J. Dionne et al., "What are the physical characteristics associated with a normal metabolic profile despite a high level of obesity in postmenopausal women?" Journal of Clinical Endocrinology and Metabolism, vol. 86, no. 3, pp. 1020-1025, 2001.

[52] X.-P. Dai, Z.-Q. Liu, L.-Y. Xu et al., "Association of plasma epinephrine level with insulin sensitivity in metabolically healthy but obese individuals," Autonomic Neuroscience, vol. 167, no. 1-2, pp. 66-69, 2012.

[53] V. A. Genelhu, B. M. J. Celoria, S. F. P. Duarte, P. H. Cabello, and E. A. Francischetti, "Not all obese subjects of multiethnic origin are at similar risk for developing hypertension and type 2 diabetes," European Journal of Internal Medicine, vol. 20, no. 3, pp. 289-295, 2009.

[54] L. Hayes, M. S. Pearce, M. J. Firbank, M. Walker, R. Taylor, and N. C. Unwin, "Do obese but metabolically normal women differ in intra-abdominal fat and physical activity levels from those with the expected metabolic abnormalities? A crosssectional study," BMC Public Health, vol. 10, article 723, 2010.

[55] A. D. Karelis, M. Faraj, J. P. Bastard et al., "The metabolically healthy but obese individual presents a favorable inflammation profile," Journal of Clinical Endocrinology and Metabolism, vol. 90, no. 7, pp. 4145-4150, 2005.

[56] N. Klöting, M. Fasshauer, A. Dietrich et al., "Insulin-sensitive obesity," American Journal of Physiology-Endocrinology and Metabolism, vol. 299, no. 3, pp. E506-E515, 2010.

[57] B. Krzyzanowska-Świniarska, A. Kempa, T. Miazgowski, and K. Pilarska, "Serum acylated ghrelin, adiponectin and leptin levels in normal-weight and obese premenopausal women," Hormone and Metabolic Research, vol. 39, no. 11, pp. 835-839, 2007.

[58] V. Messier, A. D. Karelis, M. È. Robillard et al., "Metabolically healthy but obese individuals: relationship with hepatic enzymes," Metabolism, vol. 59, no. 1, pp. 20-24, 2010.

[59] X. J. Xu, M.-S. Gauthier, D. T. Hess et al., "Insulin sensitive and resistant obesity in humans: AMPK activity, oxidative stress, and depot-specific changes in gene expression in adipose tissue," Journal of Lipid Research, vol. 53, no. 4, pp. 792-801, 2012.

[60] L. A. Lynch, J. M. O’Connell, A. K. Kwasnik, T. J. Cawood, C. O'Farrelly, and D. B. O'Shea, “Are natural killer cells protecting 
the metabolically healthy obese patient?" Obesity, vol. 17, no. 3, pp. 601-605, 2009.

[61] J. O'Connell, L. Lynch, T. J. Cawood et al., “The relationship of omental and subcutaneous adipocyte size to metabolic disease in severe obesity," PLoS One, vol. 5, no. 4, Article ID e9997, 2010.

[62] A. Koster, S. Stenholm, D. E. Alley et al., "Body fat distribution and inflammation among obese older adults with and without metabolic syndrome," Obesity, vol. 18, no. 12, pp. 2354-2361, 2010.

[63] M.-V. Robillard, P. Bellefeuille, A. S. Comtois, M. AubertinLeheudre, and A. D. Karelis, "The metabolically healthy but obese postmenopausal woman presents a favourable heart rate variability profile," Scandinavian Cardiovascular Journal, vol. 45, no. 5, pp. 316-320, 2011.

[64] S. Velho, F. Paccaud, G. Waeber, P. Vollenweider, and P. Marques-Vidal, "Metabolically healthy obesity: different prevalences using different criteria," European Journal of Clinical Nutrition, vol. 64, no. 10, pp. 1043-1051, 2010.

[65] C. L. Jennings, E. V. Lambert, M. Collins, Y. Joffe, N. S. Levitt, and J. H. Goedecke, "Determinants of insulinresistant phenotypes in normal-weight and obese black african women," Obesity, vol. 16, no. 7, pp. 1602-1609, 2008.

[66] Y. Chang, S. Ryu, B.-S. Suh, K. E. Yun, C.-W. Kim, and S.-I. Cho, "Impact of BMI on the incidence of metabolic abnormalities in metabolically healthy men," International Journal of Obesity, vol. 36, no. 9, pp. 1187-1194, 2012.

[67] R. Weiss, S. E. Taksali, S. Dufour et al., "The "Obese insulin-sensitive" adolescent: importance of adiponectin and lipid partitioning," Journal of Clinical Endocrinology and Metabolism, vol. 90, no. 6, pp. 3731-3737, 2005.

[68] F. Magkos, E. Fabbrini, B. S. Mohammed, B. W. Patterson, and S. Klein, "Increased whole-body adiposity without a concomitant increase in liver fat is not associated with augmented metabolic dysfunction," Obesity, vol. 18, no. 8, pp. 1510-1515, 2010.

[69] E. Fabbrini, F. Magkos, B. S. Mohammed et al., "Intrahepatic fat, not visceral fat, is linked with metabolic complications of obesity," Proceedings of the National Academy of Sciences of the United States of America, vol. 106, no. 36, pp. 15430-15435, 2009.

[70] E. D’Adamo, A. M. G. Cali, R. Weiss et al., "Central role of fatty liver in the pathogenesis of insulin resistance in obese adolescents," Diabetes Care, vol. 33, no. 8, pp. 1817-1822, 2010.

[71] K. Kantartzis, J. MacHann, F. Schick, A. Fritsche, H. U. Häring, and N. Stefan, "The impact of liver fat vs visceral fat in determining categories of prediabetes," Diabetologia, vol. 53, no. 5, pp. 882-889, 2010.

[72] G. Calori, G. Lattuada, F. Ragogna et al., "Fatty liver index and mortality: the cremona study in the 15th year of follow-up," Hepatology, vol. 54, no. 1, pp. 145-152, 2011.

[73] G. Perseghin, P. Scifo, F. de Cobelli et al., "Intramyocellular triglyceride content is a determinant of in vivo insulin resistance in humans: a $1 \mathrm{H}-13 \mathrm{C}$ nuclear magnetic resonance spectroscopy assessment in offspring of type 2 diabetic parents," Diabetes, vol. 48, no. 8, pp. 1600-1606, 1999.

[74] B. Elisha, A. D. Karelis, P. Imbeault, and R. Rabasa-Lhoret, "Effects of acute hyperinsulinaemia on total and highmolecular-weight adiponectin concentration in metabolically healthy but obese postmenopausal women: a MontrealOttawa New Emerging Team (MONET) study," Diabetes and Metabolism, vol. 36, no. 4, pp. 319-321, 2010.
[75] N. Stefan, F. Machicao, H. Staiger et al., "Polymorphisms in the gene encoding adiponectin receptor 1 are associated with insulin resistance and high liver fat," Diabetologia, vol. 48, no. 11, pp. 2282-2291, 2005.

[76] A. J. Cameron, "Metabolically normal obesity: a misnomer?" International Journal of Obesity, vol. 36, article 164, 2012.

[77] J. W. McEvoy, M. J. Blaha, and K. Nasir, "Metabolically benign' obesity: a wolf in sheep's clothing," Atherosclerosis, vol. 217, no. 1, pp. 74-76, 2011.

[78] Z. Pataky, E. Bobbioni-Harsch, and A. Golay, "Open questions about metabolically normal obesity," International Journal of Obesity, vol. 34, supplement 2, pp. S18-S23, 2010.

[79] M. Blüher, "Adipose tissue dysfunction in obesity," Experimental and Clinical Endocrinology and Diabetes, vol. 117, no. 6, pp. 241-250, 2009.

[80] H. Bays, L. Mandarino, and R. A. DeFronzo, "Role of the adipocyte, free fatty acids, and ectopic fat in pathogenesis of type 2 diabetes mellitus: peroxisomal proliferator-activated receptor agonists provide a rational therapeutic approach," Journal of Clinical Endocrinology and Metabolism, vol. 89, no. 2, pp. 463-478, 2004.

[81] D. O. Okorodudu, M. F. Jumean, V. M. Montori et al., "Diagnostic performance of body mass index to identify obesity as defined by body adiposity: a systematic review and meta-analysis," International Journal of Obesity, vol. 34, no. 5, pp. 791-799, 2010.

[82] J. W. Lee, H. R. Lee, J. Y. Shim et al., "Viscerally obese women with normal body weight have greater brachial-ankle pulse wave velocity than nonviscerally obese women with excessive body weight," Clinical Endocrinology, vol. 66, no. 4, pp. 572578, 2007.

[83] D. C. Robbins, L. Andersen, R. Bowsher et al., "Report of the American Diabetes Asociation's task force on standardization of the insulin assay," Diabetes, vol. 45, no. 2, pp. 242-256, 1996.

[84] L. Heinemann, "Insulin assay standardization: leading to measures of insulin sensitivity and secretion for practical clinical care-response to Staten et al," Diabetes Care, vol. 33, no. 6 , p. e83, 2010.

[85] M. S. Sridhar, C. D. Jarrett, J. W. Xerogeanes, and S. A. Labib, "Obesity and symptomatic osteoarthritis of the knee," Journal of Bone and Joint Surgery B, vol. 94, no. 4, pp. 433-440, 2012.

[86] A. D. Karelis, J. Fontaine, R. Rabasa-Lhoret et al., "Psychosocial profile of the metabolically healthy but obese postmenopausal woman," Diabetes and Metabolism, vol. 32, no. 1, pp. 90-91, 2006.

[87] R. M. Puhl and C. A. Heuer, "Obesity stigma: important considerations for public health," American Journal of Public Health, vol. 100, no. 6, pp. 1019-1028, 2010. 


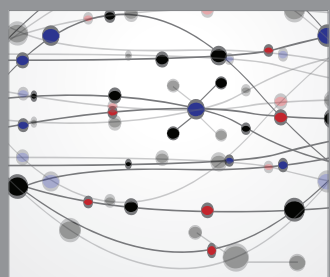

The Scientific World Journal
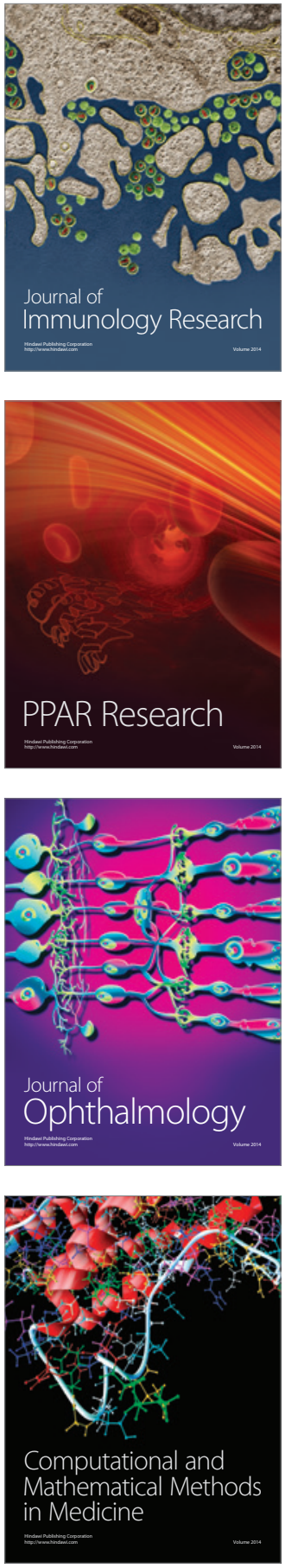

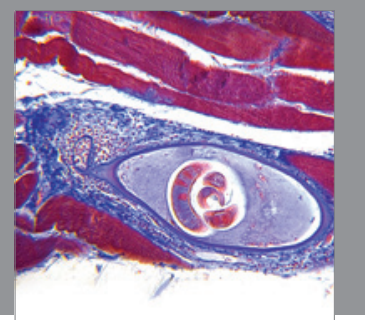

Gastroenterology

Research and Practice
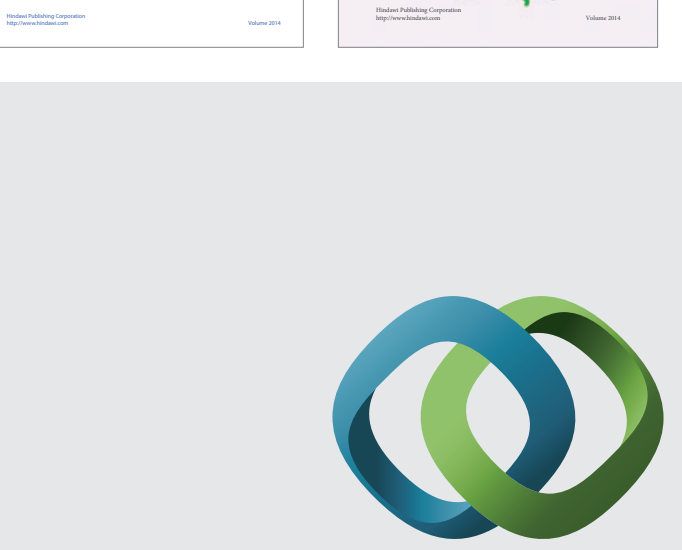

\section{Hindawi}

Submit your manuscripts at

http://www.hindawi.com
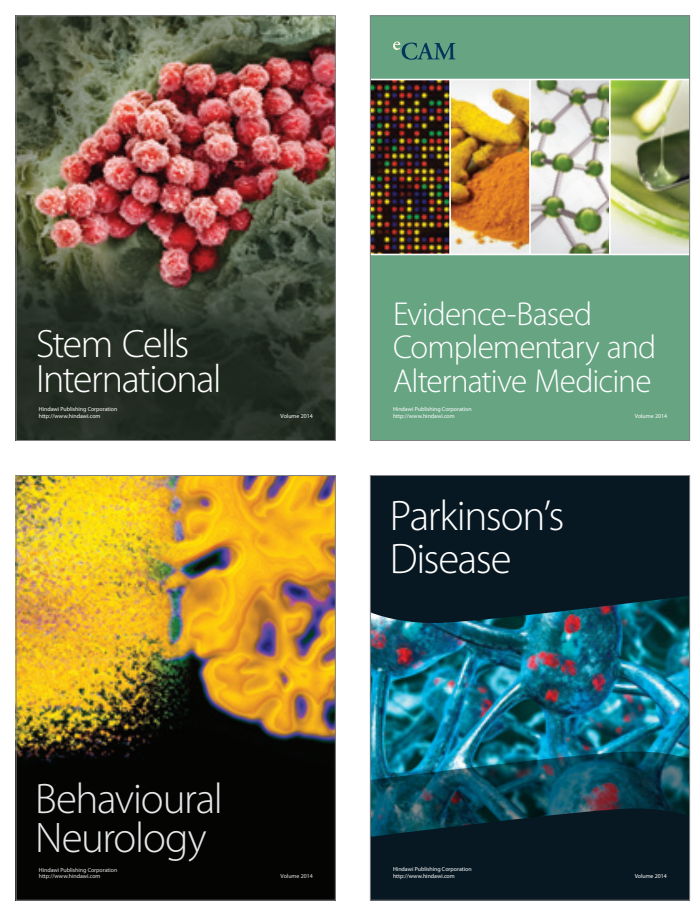

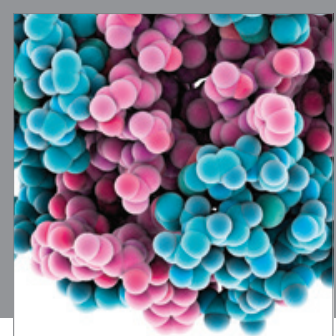

Journal of
Diabetes Research

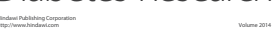

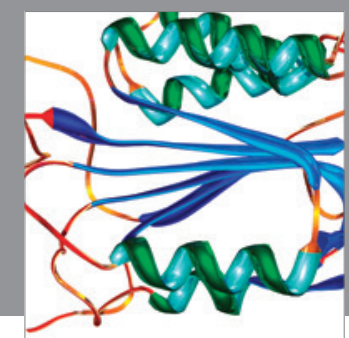

Disease Markers
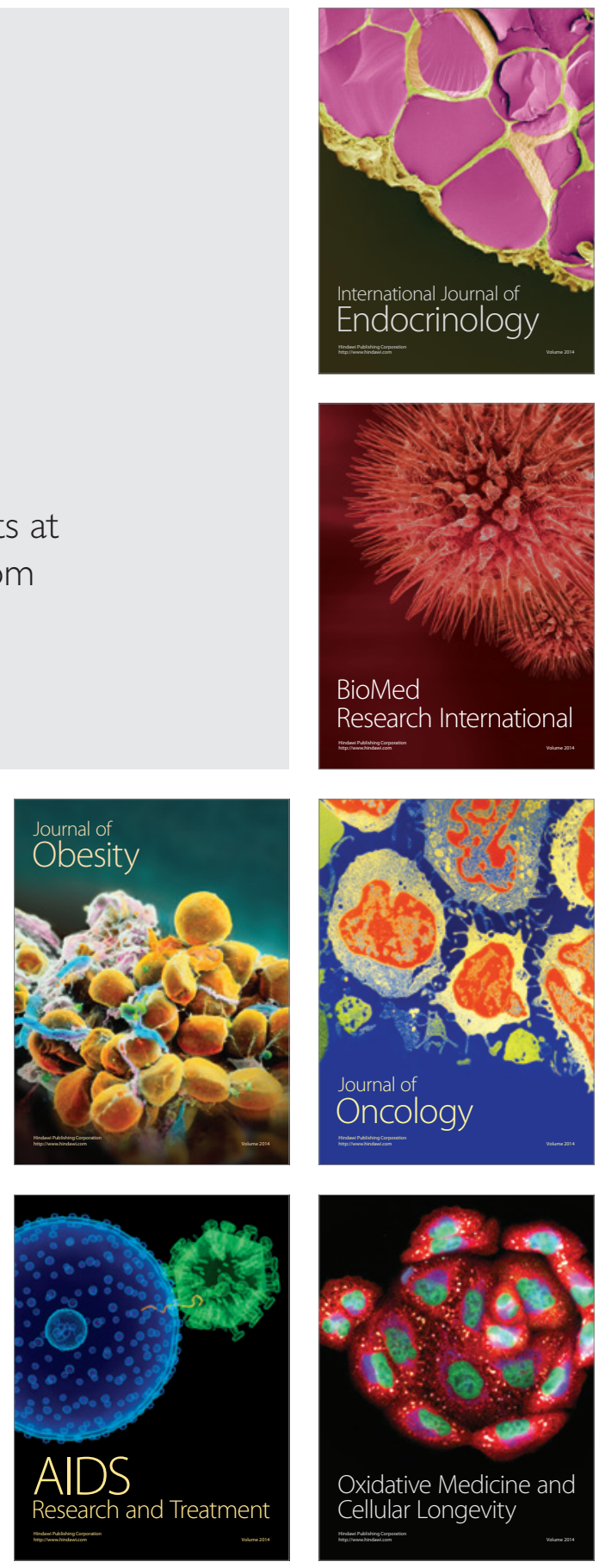